\title{
Effectiveness of Image-guided Brachytherapy in Patients With Locally Advanced Cervical Squamous Cell Carcinoma Receiving Concurrent Chemoradiotherapy
}

\author{
SHANG-WEN CHEN ${ }^{1,2,3}$, JI-AN LIANG ${ }^{1,2}$, YAO-CHING HUNG ${ }^{2,4}$, \\ LIAN-SHUNG YEH ${ }^{4}$, WEI-CHUN CHANG ${ }^{2,4}$, WU-CHOU LIN ${ }^{2,4,5}$ and YIN-YI CHANG ${ }^{4,5}$ \\ ${ }^{1}$ Department of Radiation Oncology, China Medical University Hospital, Taichung, Taiwan, R.O.C.; \\ ${ }^{2}$ Graduate Institute of Clinical Medical Science, School of Medicine, \\ College of Medicine, China Medical University, Taichung, Taiwan, R.O.C.; \\ ${ }^{3}$ Department of Radiology, School of Medicine, Taipei Medical University, Taipei, Taiwan, R.O.C.; \\ ${ }^{4}$ Department of Obstetrics and Gynecology, China Medical University Hospital, Taichung, Taiwan, R.O.C.; \\ ${ }^{5}$ College of Chinese Medicine, China Medical University, Taichung, Taiwan, R.O.C.
}

\begin{abstract}
Aim: To compare the advantage of image-guided brachytherapy (IGBT) over conventional two-dimensional brachytherapy (2DBT) in patients with advanced cervical squamous cell carcinoma. Patients and Methods: This study included 253 patients with stage IB2-IVA diseases treated with two schemes of brachytherapy. One hundred and thirtysix patients received $2 D B T$, whereas 117 patients received IGBT. Tumor stage, age, and tumor diameter were matched between the two groups. Local relapse-free survival, overall survival, and cumulative incidences of gastrointestinal and genitourinary complications were compared between the two groups. Results: The overall and local relapse-free survival rates were similar between the two groups. The cumulative rate of grade 2 and higher gastrointestinal complication was $21.3 \%$ for the $2 D B T$ group, and $8.5 \%$ for the IGBT group $(p=0.007)$, whereas that of grade 2 and higher genitourinary injury was $11.8 \%$ for the 2DBT group, and $1.7 \%$ for the IGBT group $(p=0.002)$. Conclusion: In patients with advanced cervical squamous cell carcinoma, IGBT achieves a higher therapeutic ratio compared to 2DBT technique by minimizing the late toxicities.
\end{abstract}

Cervical cancer remains one of the leading causes of cancerrelated deaths in women worldwide (1). In patients with intact uterus, the use of image-guided brachytherapy (IGBT)

Correspondence to: Shang-Wen Chen, Department of Radiation Oncology, China Medical University Hospital, No. 2, Yuh-Der Road, Taichung, 404 Taiwan, R.O.C. Tel: +886 422052121, ext 7450, Fax: +886 422052121, ext 7460, e-mail: vincent1680616@yahoo.com.tw

Key Words: Cervical cancer, intensity-modulated radiation therapy, image-guided brachytherapy, therapeutic ratio. has grown considerably because of the introduction of an adaptive target concept and a dose volume assessment balancing constraints for clinical target volume (CTV) and organ at risk (OAR) (2-10). A series of single institutional studies demonstrated an increased therapeutic ratio when compared to conventional two-dimensional brachytherapy (2DBT) $(2,5)$. Although current findings suggest a favorable impact of IGBT on outcomes, so far, no randomized trial has been conducted to validate its benefits over 2DBT probably due to ethical concerns.

In definitive chemoradiotherapy (CRT) for locally advanced cervical cancer, in which brachytherapy is an essential component of radiotherapy, the net impact of advanced technique using IGBT on final outcome has been reported by a prospective international study on magnetic resonance imaging (MRI) based brachytherapy in cervical cancer (EMBRACE) (9). The results showed that IGBT leads to excellent local control and pelvic control (91\% and 87\% at 3 years) and overall survival ( $74 \%$ at 3 years) with limited severe morbidity (9). However, IGBT is a more timeconsuming process requiring individualized contouring and planning. It also requires additional resources such as realtime images and availability of 3D treatment planning systems. The additional costs of setting up IGBT are more than the normal costs of the conventional brachytherapy procedure (11). In some developing countries, not all cancer patients requiring brachytherapy are able to receive adequate treatment (12). Furthermore, patients who can undergo routine IGBT might be restricted in some institutes where patient load was huge. Therefore, this retrospective study was conducted to examine the hypothesis that IGBT may potentially gain more therapeutic effect. All the studied patients were treated with the similar technique and dosage of external-beam radiotherapy (EBRT) using intensity- 
modulated radiation therapy (IMRT) and concurrent chemotherapy. The result will be helpful to institutions where the cost-effectiveness of modern technique is a concern, particularly where resources are limited.

\section{Patients and Methods}

Patients. This retrospective cohort study included patients with stage IB2-IVA cervical squamous cell carcinoma, according to the International Federation of Gynecology and Obstetrics (FIGO) staging system, treated with curative CRT in two treatment periods between January 2007 and December 2016. In 2018, staging has been revised by the FIGO Gynecologic Oncology Committee to allow imaging and pathological findings to assign the stage (13). Therefore, both old and new FIGO stages were applied. To minimize the bias in this comparative study, patients with a histological type of adenocarcinoma or adenosquamous carcinoma were excluded because they have inferior outcomes compared with those with squamous cell carcinoma when primarily treated with CRT $(14,15)$. All patients received comprehensive pretreatment workup, including computed tomography (CT), and completed an allocated CRT course. Figure 1 presents the flowchart of patient selection and study design.

The patients in the first period received IMRT plus 2DBT and were labeled 2DBT group, whereas patients after 2012 were irradiated with IMRT plus IGBT, referred to as IGBT group. A total of 253 cases were included in this comparative study, and sample size for 2DBT and IGBT group was 136 and 117, respectively. Tumor stage, age, and tumor diameter were matched between the two groups, while were treated by the same radiation oncology team. Patient characteristics are summarized in Table I. The study was approved by the institutional review board [CMUH107-REC3-19].

External beam radiotherapy. All patients underwent CT-based planning with custom immobilization. Both groups were initially irradiated with an IMRT technique with a prescribed dose to the whole pelvis of $45 \mathrm{~Gy}$ in 25 fractions (16). Following the IMRT, bilateral parametrial disease was boosted to 50.4 to 54.0 Gy via anterior and posterior parallel fields with central shielding. In patients with radiologically metastatic pelvic lymph nodes, the involved nodes were further irradiated with IMRT to a cumulative dose of 60 to $64 \mathrm{~Gy}$. The CTV of the initial IMRT included the gross disease, cervix, parametrium, uterus, superior half of the vagina, cardinal ligament, presacral region, and regional lymph nodes (common, internal, and external iliac) as similar with consensus guidelines on CTV delineation $(17,18)$. Uniform planning margins were added to account for organ motion and setup uncertainty. We applied a $15-\mathrm{mm}$ planning margin around the cervix, a 10-mm margin around the uterus and the vagina, and an $8-\mathrm{mm}$ margin around the remainder of the CTV according to previous studies (19). Target planning constraints were standardized and previously described (16).

Image-guided radiotherapy using kilo-voltage imaging, and cone beam CT to minimize geometrical uncertainties for daily treatment setup was not routinely employed. This technique was implemented by individual choice, and the proportion of the use for 2DBT and IGBT groups was $19 \%$ and $21 \%$, respectively.

Brachytherapy. Following 45 Gy to the pelvis, high-dose rate intracavitary brachytherapy was performed using an Ir-192 remote after-loading technique after adequate tumor regression and concurrently with pelvic irradiation or parametrial boosting. In the 2DBT group, the standard prescribed dose for each 2DBT was $6.0 \mathrm{~Gy}$ to Point A for 4 sessions. The Point A dose was reduced to 5.0 Gy for those with higher reference doses to the rectum or bladder, or those aged over 70 years. The total prescribed Point A doses (external beam + brachytherapy) ranged from 65.6 to $75 \mathrm{~Gy}$ (median, $69 \mathrm{~Gy}$ ). The details of the 2DBT have been reported previously (20).

In IGBT group, gross tumor volume (GTV) and high-risk CTV (HR-CTV) were contoured on pelvic MRI that was done prior to the first secession of IGBT. Using image registration technique, the MRI-based target volumes were then fused with applicator-based simulation CT on the first IGBT. Planning volumes were according to the GEC-ESTRO guidelines (21). Thereafter, individual dose optimization of the subsequent application was based on the transferred MRI target volume and OAR structures delineated on CT. A dose-volume histogram was calculated according to CT-based HR-CTV and OAR. The brachytherapy was performed by commercial treatment planning system (Varian GammaMedplus ix, Palo Alto, CA, USA). Intracavitary applicators with Henschke T\&O applicator consisting of tandem and ovoids (Mick Radio-Nuclear Instruments, Inc., Mount Vernon, NY, USA) were used for insertion. Dose volume adaptation was performed with the aim of dose of cumulative equivalent dose in 2 Gy per fraction (EQD2) of HRCTV-D90 $>80$ Gy. The mean HR-CTV was $34.5 \pm 15.5 \mathrm{ml}$ (range=14.0-150.4), and the mean cumulative EQD2 of HR-CTV$\mathrm{D} 90$ was $87.6 \pm 7.9 \mathrm{~Gy}_{10}$ (range=71.9-110.1). The mean cumulative EQD2 of doses for the most exposed 2cc (D2cc) for rectum, bladder, and sigmoid colon were $60.9 \pm 6.4 \mathrm{~Gy}_{3}, 67.1 \pm 8.6 \mathrm{~Gy}_{3}$, and $64.8 \pm 6.9 \mathrm{~Gy}_{3}$, respectively.

Chemotherapy. Chemotherapy consisted of cisplatin delivered weekly at a dose of $40 \mathrm{mg} / \mathrm{m}^{2}$ intravenously, with a total maximal dose of up to $60 \mathrm{mg}$. The first cycle of cisplatin was initiated at the first radiotherapy (RT) treatment. In accordance with the duration of RT, the treatment plan included a total of five to eight cycles of cisplatin (16).

Follow-up. After completion of radiotherapy, patients received regular follow-up every 2 months for the first year, and every 3 months afterward. A pelvic examination was performed during each follow-up; in addition, tumor markers (squamous cell carcinoma antigen and carcinoembryonic antigen) were checked. A CT scan was carried out every 6 months for the first 2 years and routine urine and stool examinations were done every 6 to 12 months. Patients who had persistent abdominal pain, bloody stools or hematuria underwent sigmoidoscopy or cystoscopy to identify the source of bleeding, and underwent blood counts for surveillance of the severity of the complications. Common Terminology Criteria for Adverse Events Version 4.0 was used to score the maximum late toxicities, including gastrointestinal (GI) and genitourinary (GU) complications (22).

Study endpoints and statistical analysis. The primary endpoints were local relapse-free survival (LRFS) and cumulative incidences of grade 2 or more complications of adjacent GI or GU tracts because of the association with the direct treatment efficacy across three treatment regimes. A comparison of the categorical and continuous variables among groups was performed using the ANOVA and Chisquare test. A multivariate analysis using binary logistic regression was carried out to estimate the odds ratio (OR) of complications among the variables examined. Overall survival (OS) and LRFS 


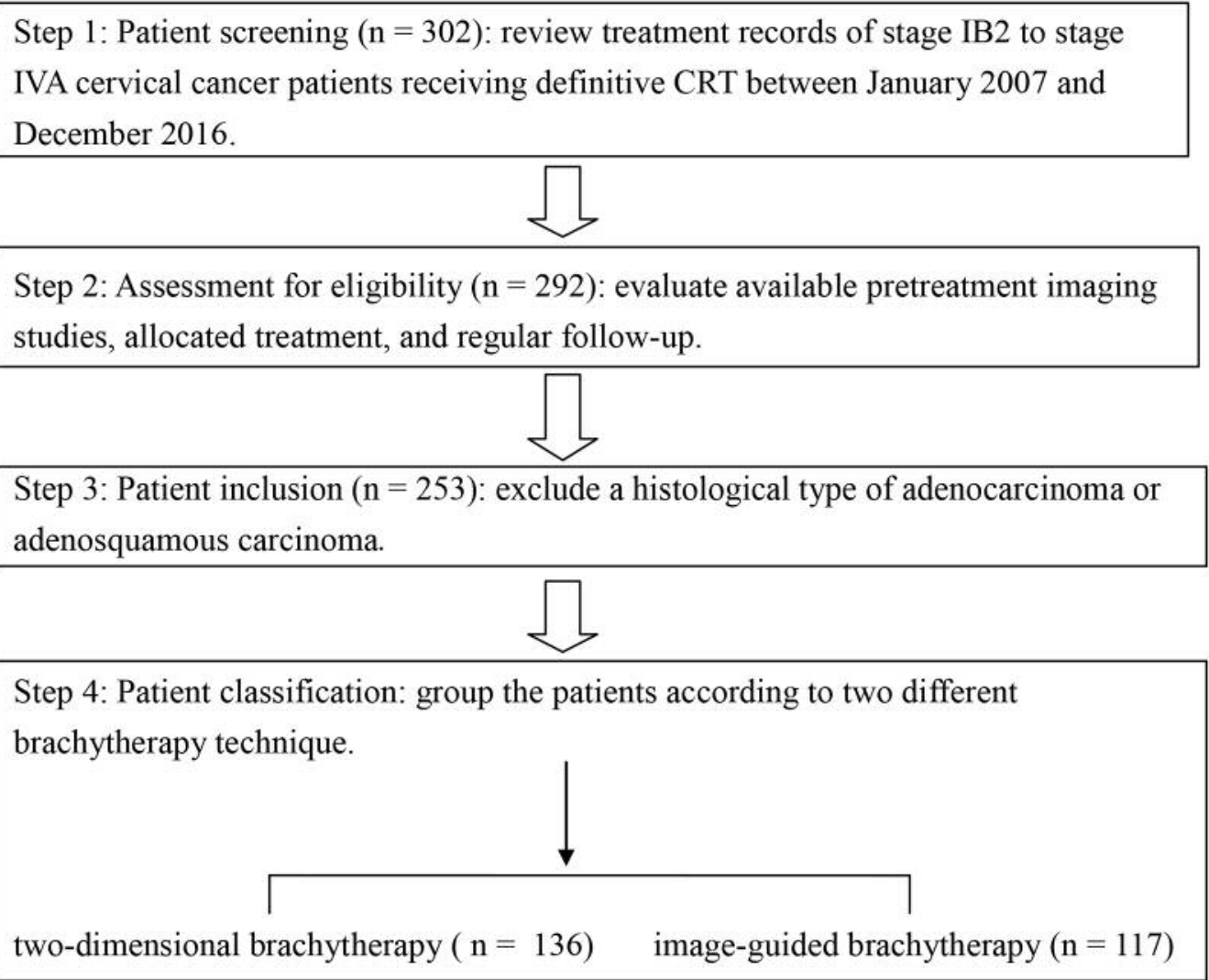

Figure 1. The flowchart of patient selection and study design.

were calculated using the Kaplan-Meier method. The log-rank test and Cox regression analysis were performed to examine the effects of explanatory variables on these endpoints. Statistical significance was considered when a two-sided $p$-value was $<0.05$. Patient survival was measured from the date of radiotherapy initiation to the last follow-up. The latency of complications was measured from the end of radiotherapy to the last follow-up. All statistical analyses were performed using a commercial software package (SPSS 13.0 for Windows, Chicago, IL, USA)

\section{Results}

Within a median follow-up duration of 60 months for the 2DBT group and 47 months for the IGBT group, 187 patients were alive and 66 patients had died. Moreover, 198 patients had no evidence of disease progression, whereas 55 patients had disease progression (infield recurrence, distant metastasis, and both in 28, 41, and 14 patients, respectively). Among the 28 patients with infield recurrence, one experienced sole pelvic lymph node relapse. In summary, 226 patients remained relapse-free at primary sites, whereas 27 patients experienced local recurrence. As depicted in Figures 2 and 3, the 4-year LRFS for 2DBT and IGBT groups was $89 \%$ and $87 \%(p=0.68)$, whereas the 4-year OS for 2DBT and IGBT groups was $70 \%$ and $76 \%(p=0.32)$, respectively. Table II lists the result of the Cox regression analyses and disclosed that IGBT did not lead to a superior outcome in terms of OS or LRFS. The adverse features for OS were new stage IIIA-IVA disease [ $p=0.04$, hazard ratio (HR) $1.21,95 \%$ confidence interval $(\mathrm{CI})=1.01-1.47]$ and existence of paraaortic lymph node metastasis $(p=0.005, \mathrm{HR}$ 2.36, 95\% CI=1.32-4.28), whereas prognostic factors for LRFS were age 65 years $(p=0.024, \mathrm{HR}=3.47,95 \% \mathrm{CI}=1.36-$ $8.33)$ and new stage IIIA-IVA disease $(p=0.027, \mathrm{HR}=1.43$, 95\%CI=1.04-1.96), respectively. Subgroup analysis was carried out for IGBT group (Table III). The evidence of obstructive uropathy and HR-CTV values were two predictors for inferior LRFS in the Cox regression analysis. The cumulative EQD2 to the HR-CTV was not associated with local failure.

The incidences of various endpoints of GI or GU toxicities across the treatment groups are summarized in Table IV. The median duration of GI and GU complication was 15 months (range=4-29) and 27 months (range=3-56), respectively. The cumulative rate of grade 2 and higher GI complication was 
Table I. Patient characteristics.

\begin{tabular}{|c|c|c|c|}
\hline Characteristics & $\begin{array}{l}\text { 2DBT group } \\
(\mathrm{n}=136) \\
\text { Mean }(\%)\end{array}$ & $\begin{array}{c}\text { IGBT group } \\
(\mathrm{n}=117) \\
\text { Mean }(\%)\end{array}$ & $p$-Value \\
\hline Age (years)** & $57(31-79)$ & $59(28-78)$ & 0.12 \\
\hline$<45$ & $16(11.8 \%)$ & $12(10.3 \%)$ & \\
\hline $45-65$ & $81(59.5 \%)$ & $68(58.1 \%)$ & \\
\hline$>65$ & $39(28.7 \%)$ & $37(31.6 \%)$ & \\
\hline Stage (old) & & & 0.78 \\
\hline IB2 & $23(16.9 \%)$ & $23(19.7 \%)$ & \\
\hline II & $70(51.5 \%)$ & $61(52.1 \%)$ & \\
\hline III-IVA & $43(31.6 \%)$ & $33(28.2 \%)$ & \\
\hline Stage (new) & & & 0.23 \\
\hline IB3 & $15(11.0 \%)$ & $7(6.0 \%)$ & \\
\hline II & $45(33.1 \%)$ & $40(33.6 \%)$ & \\
\hline III-IVA & $76(55.9 \%)$ & $70(59.8 \%)$ & \\
\hline Tumor size & & & 0.70 \\
\hline$<4 \mathrm{~cm}$ & $32(23.5 \%)$ & $27(23.1 \%)$ & \\
\hline$\geq 4 \mathrm{~cm}$ & $104(76.5 \%)$ & $90(76.9 \%)$ & \\
\hline Pelvic lymph node & & & 0.85 \\
\hline Negative & $77(56.6 \%)$ & $60(51.3 \%)$ & \\
\hline Positive & $59(43.4 \%)$ & $57(48.7 \%)$ & \\
\hline Paraaortic lymph node & & & 0.64 \\
\hline Negative & $118(86.8 \%)$ & $101(86.3 \%)$ & \\
\hline Positive & $18(13.2 \%)$ & $16(13.7 \%)$ & \\
\hline Obstructive uropathy & & & 0.60 \\
\hline Negative & $117(86.0 \%)$ & $105(89.7 \%)$ & \\
\hline Positive & $19(14.0 \%)$ & $12(10.3 \%)$ & \\
\hline RT duration (days)** & $\begin{array}{c}51 \sim 101 \\
\text { (median 60) }\end{array}$ & $\begin{array}{c}48 \sim 99 \\
\text { (median 56) }\end{array}$ & 0.57 \\
\hline Cisplatin cycle (mean) & 5.9 & 5.9 & 0.88 \\
\hline Follow-up (months)** & $\begin{array}{c}5 \sim 120 \\
\text { (median 60) }\end{array}$ & $\begin{array}{c}6 \sim 66 \\
\text { (median 47) }\end{array}$ & 0.006 \\
\hline
\end{tabular}

2DBT, Two-dimensional brachytherapy; IGBT, image-guided brachytherapy; RT, radiotherapy. *Continuous variables were examined by ANOVA test., whereas categorical variables were tested by Chisquare test. **Data presented as median (range).

$21.3 \%$ for 2DBT group and $8.5 \%$ for IGBT group ( $p=0.007$ ), whereas that of grade 2 and higher GU injury was $11.8 \%$ for the 2DBT group and $1.7 \%$ for the IGBT group $(p=0.002)$. The actuarial hazard curves are depicted in Figure 4. The 4-year actuarial GI complication rate was $27 \%$ for 2DBT group and $10 \%$ for IGBT group $(p=0.022)$, whereas that of GU complication rate was $17 \%$ for $2 \mathrm{DBT}$ group and $3 \%$ for IGBT group $(p=0.017)$. The cumulative rate of grade 3 and higher complication was $10.3 \%$ for $2 \mathrm{DBT}$ group and $1.7 \%$ for IGBT group ( $p=0.03$ ), whereas that of grade 3 and higher GU injury was $4.4 \%$ for 2DBT group and $0.9 \%$ for IGBT group ( $p=0.08$ ). According to most endpoints, 2DBT group experienced a higher probability of late complications compared with IGBT group.

Using toxicity profile of 2DBT group as a reference, Table $\mathrm{V}$ indicates that the independent factors which decreased grade 2 and higher GI toxicities was the application of the IGBT
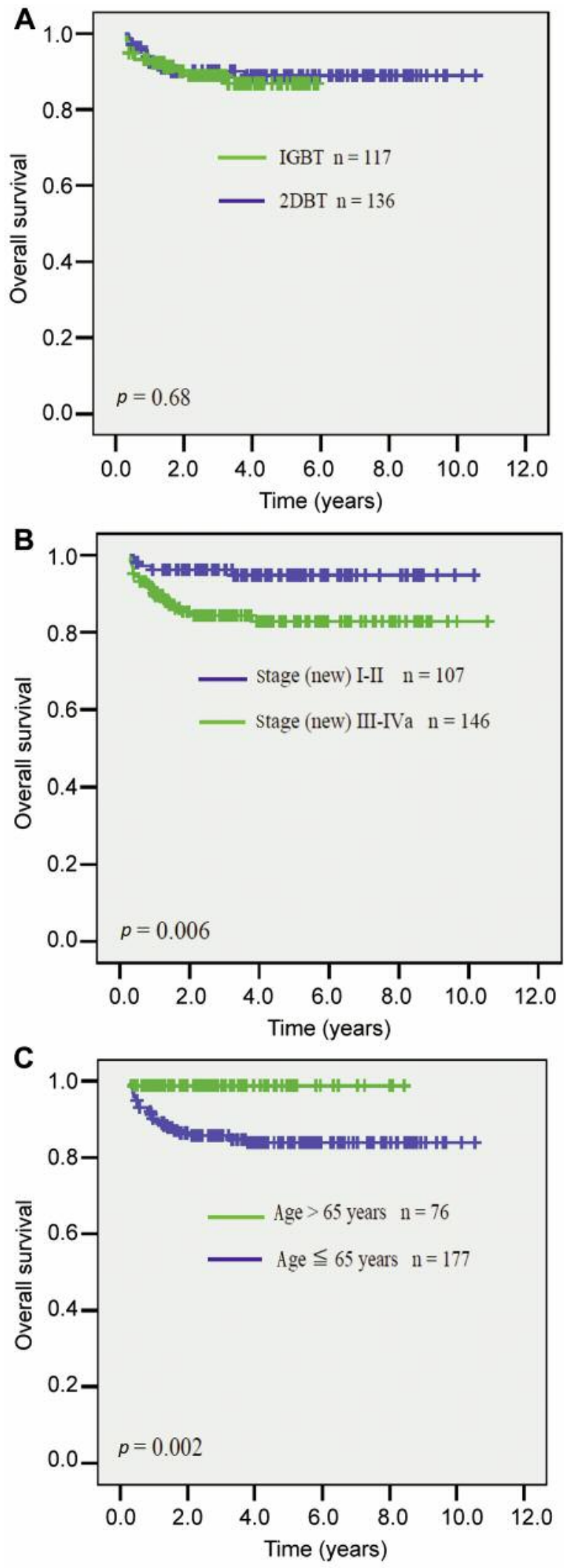

Figure 2. Local relapse-free survival curves according to the treatment groups $(A)$, stage $(B)$, and age $(C)$. 

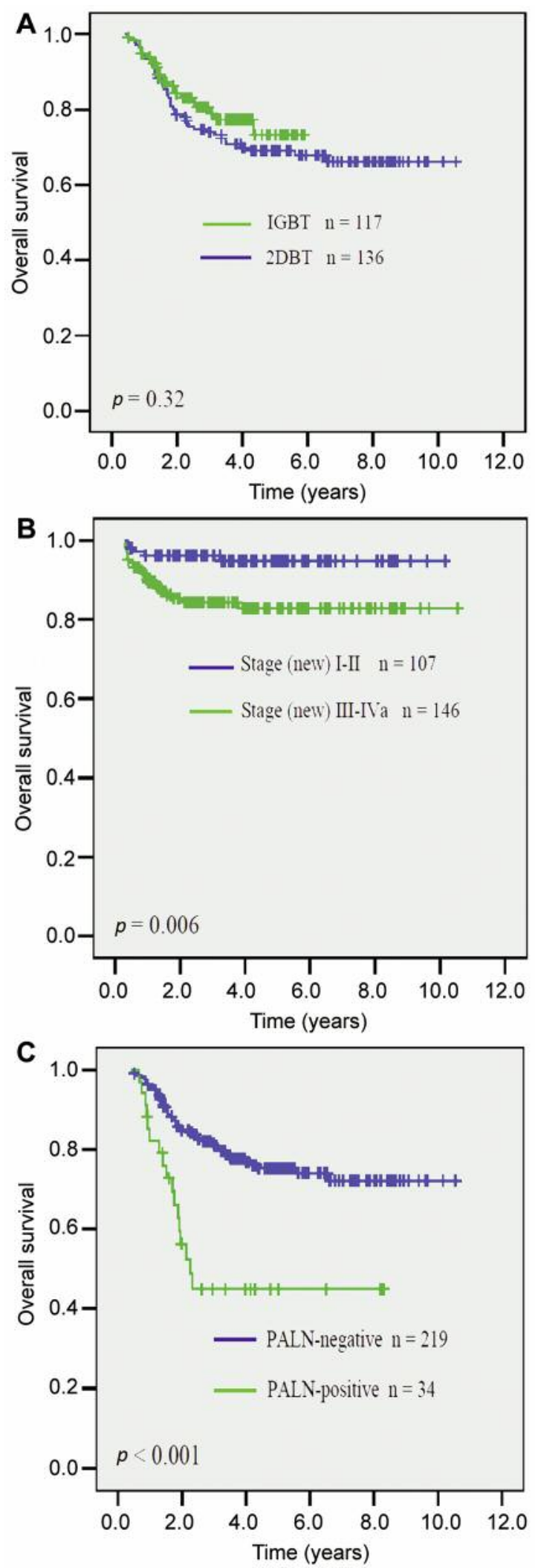

Figure 3. Overall survival curves according to the treatment groups (A), stage $(B)$, and paraaortic lymph node status $(C)$.
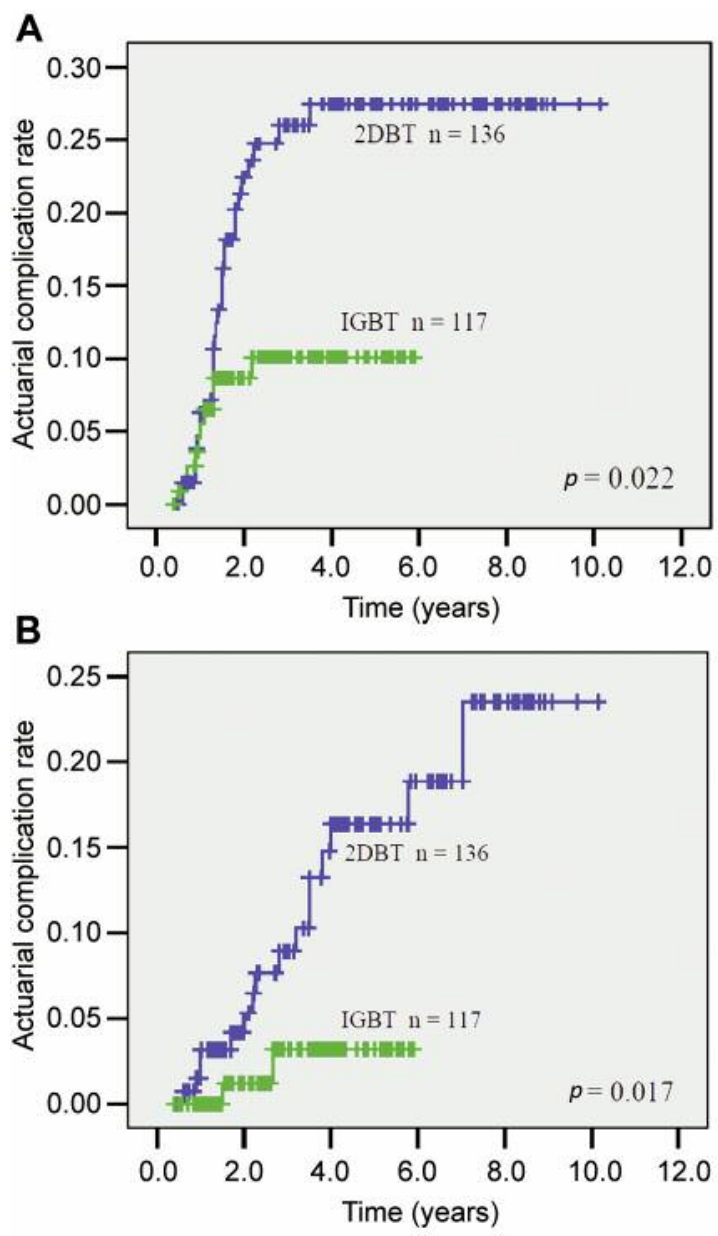

Figure 4. Actuarial rates for late grade 2 and above complication of the gastrointestinal (A) and genitourinary tract $(B)$ according to the treatment groups.

$[p=0.015$, odds ratio $(\mathrm{OR})=0.40,95 \% \mathrm{CI}=0.19-0.84]$. The IGBT also contributed the reduction of grade 2 and higher GU complications $(p=0.009, \mathrm{OR}=0.14,95 \% \mathrm{CI}=0.05-0.69)$. When lumping any events with grade 2 or above GI or GU complications together, the employing the IGBT decreased the risk of late sequalae $(p=0.001, \mathrm{OR}=0.30,95 \% \mathrm{CI}=0.15-0.60)$. In addition, the IGBT could reduce grade 3 and higher GI or GU toxicities $(p=0.003, \mathrm{OR}=0.10,95 \% \mathrm{CI}=0.02-0.45)$.

\section{Discussion}

In patients with advanced cervical cancer, it would be not ethically feasible to conduct phase 3 trials to compare the advantage of IGBT over conventional 2DBT. Another barrier of cost-effectiveness analysis was that the impact of EBRT techniques should be assessed together due to the cumulative effect. Using the two matching cohorts with uniform EBRT and the same histology, we first disclosed the impact of 
Table II. Cox regression analysis results for the patients and treatment-related parameters associated with overall survival (OS) and local relapsefree survival (LRFS).

\begin{tabular}{|c|c|c|c|c|c|c|c|c|}
\hline \multirow[t]{3}{*}{ Variables } & \multicolumn{3}{|c|}{ OS } & \multicolumn{5}{|c|}{ LRFS } \\
\hline & \multicolumn{2}{|l|}{ Univariate } & \multicolumn{2}{|l|}{ Multivariate } & \multirow{2}{*}{$\frac{\text { Univariate }}{p \text {-Value }}$} & \multicolumn{3}{|c|}{ Multivariate } \\
\hline & $p$-Value & $p$-Value & HR & $95 \% \mathrm{CI}$ & & $p$-Value & HR & $95 \% \mathrm{CI}$ \\
\hline Age (years) $>65 v s . \leq 65$ & 0.39 & 0.18 & & & 0.002 & 0.024 & 3.47 & $1.36 \sim 8.33$ \\
\hline \multicolumn{9}{|l|}{ FIGO stage (old) } \\
\hline IB2-IIB $v s$. IIB-IVA & 0.006 & 0.40 & & & 0.39 & 0.45 & & \\
\hline \multicolumn{9}{|l|}{ FIGO stage (new) } \\
\hline IB3-IIB $v s$. IIIA-IVA & 0.003 & 0.04 & 1.21 & $1.01 \sim 1.47$ & 0.005 & 0.027 & 1.43 & $1.04 \sim 1.96$ \\
\hline \multicolumn{9}{|l|}{ Pelvic lymph node } \\
\hline Negative $v s$. positive & 0.014 & 0.89 & & & 0.014 & 0.67 & & \\
\hline \multicolumn{9}{|l|}{ Paraaortic lymph node } \\
\hline Negative $v s$. positive & $<0.001$ & 0.005 & 2.36 & $1.30 \sim 4.28$ & 0.022 & 0.37 & & \\
\hline \multicolumn{9}{|l|}{ Initial obstructive uropathy } \\
\hline Negative $v s$. positive & 0.007 & 0.17 & & & 0.26 & 0.60 & & \\
\hline \multicolumn{9}{|l|}{ Brachytherapy number } \\
\hline $4 v s . \geq 5$ & 0.38 & 0.63 & & & 0.08 & 0.19 & & \\
\hline 2DBT vs. IGBT & 0.36 & 0.26 & & & 0.50 & 0.38 & & \\
\hline
\end{tabular}

HR, Hazard ratio; CI, confidence interval; FIGO, International Federation of Gynecology and Obstetrics; 2DBT, two-dimensional brachytherapy; IGBT, image-guided brachytherapy; RT, radiotherapy.

Table III. Multivariate Cox regression analysis for tumor- or treatment-related parameters associated with local relapse-free survival in patients receiving image-guided brachytherapy (IGBT).

\begin{tabular}{|c|c|c|c|c|}
\hline \multirow[t]{3}{*}{ Variables } & \multicolumn{4}{|c|}{ Local relapse-free survival } \\
\hline & \multirow{2}{*}{$\frac{\text { Univariate mode }}{p \text {-Value }}$} & \multicolumn{3}{|c|}{ Multivariate analysis } \\
\hline & & $p$-Value & HR & $95 \% \mathrm{CI}$ \\
\hline Age (years) $>65 v s . \leq 65$ & 0.03 & 0.055 & 7.14 & $0.96-30.73$ \\
\hline \multicolumn{5}{|l|}{ FIGO stage (old) } \\
\hline IB2-IIB $v s$. IIB-IVA & 0.30 & 0.84 & & \\
\hline \multicolumn{5}{|l|}{ FIGO stage (new) } \\
\hline IB3-IIB $v s$. IIIA-IVA & 0.05 & 0.29 & & \\
\hline \multicolumn{5}{|l|}{ Pelvic lymph node } \\
\hline \multicolumn{5}{|l|}{ Paraaortic lymph node } \\
\hline negative $v s$. positive & 0.01 & 0.337 & & \\
\hline \multicolumn{5}{|l|}{ Initial obstructive uropathy } \\
\hline negative $v s$. positive & 0.009 & 0.013 & 5.71 & $1.45-22.54$ \\
\hline HR-CTV (continuous) & 0.017 & 0.04 & 1.04 & $1.01-1.08$ \\
\hline EQD2 of HR-CTV-D90 (continuous) & 0.76 & 0.93 & & \\
\hline
\end{tabular}

HR, Hazard ratio; CI, confidence interval; FIGO, International Federation of Gynecology and Obstetrics; HR-CTV, high-risk clinical target volume; EQD2, equivalent dose in 2 Gy per fraction.

IGBT on reduction of major complications for these patients. Although a longer follow-up duration for IGBT group would be ideal to confirm the differences, our findings could provide where the cost-effectiveness of modern technique is a concern, particularly where resources are limited.
For patients with locally advanced cervical cancer, this is a pilot study to compare the clinical outcome of IMRT plus IGBT over IMRT plus 2DBT. Although the application of IMRT technique is believed to result in the OARs being exposed to a lower dose of radiation and consequently 
Table IV. Cumulative rate of late gastrointestinal (GI) and genitourinary $(G U)$ toxicities according to treatment groups.

\begin{tabular}{lccc}
\hline Variables & $\begin{array}{c}\text { 2DBT (n=136) } \\
\mathrm{n}(\%)\end{array}$ & $\begin{array}{c}\text { IGBT (n=117) } \\
\mathrm{n}(\%)\end{array}$ & $p$-Value* \\
\hline Grade 2 GI & $29(21.3)$ & $10(8.5)$ & 0.007 \\
$\geq$ Grade 3 GI & $14(10.3)$ & $2(1.7)$ & 0.03 \\
$\geq$ Grade 2 GU & $16(11.8)$ & $2(1.7)$ & 0.002 \\
$\geq$ Grade 3 GU & $6(4.4)$ & $1(0.9)$ & 0.08 \\
$\geq$ Grade 2 GI or GU & $39(28.7)$ & $12(10.3)$ & $<0.001$ \\
$\geq$ Grade 3 GI or GU & $19(14.0)$ & $3(2.6)$ & 0.01 \\
\hline
\end{tabular}

2DBT, Two-dimensional brachytherapy; IGBT, image-guided brachytherapy. *Categorical outcome for two groups were examined by Chi-square test.

reduced toxicities, phase 3 studies compared IMRT with non-IMRT techniques remain limited in the setting of definitive CRT $(23,24)$. Hasselle et al. (25) reported the rate of grade 3 and greater complications in 89 patients with intact cervix treated with IMRT plus low-dose rate brachytherapy was $4 \%$ and $5 \%$ for GI and GU system, respectively. In addition, Kidd et al. (26) showed a great difference in the incidence of late toxicities between the groups. The IMRT group had only a $6 \%$ rate of Grade 3 or greater GI or GU toxicity, versus $17 \%$ for the non-IMRT group ( $p=0.0017)$. Taken together, the application of IMRT ought to be one of the determinants of late toxicities when using conventional brachytherapy.

Unlike those treated in the postoperative setting, in which irradiation dose is mainly prescribed by EBRT, brachytherapy always plays an important role in determining the final outcome for patients with an intact uterus. Thus, IGBT is major approach that might be used to increase therapeutic ratio. In this study, the control rate was comparable to other international studies (2-10). Although the mean total EQD2 of HR-CTV-D90 for IGBT group was 87.6 $\mathrm{Gy}_{10}$, the dose-response curve was not obvious. Dimopoulos et al. studied a cohort of 141 patients with cervical cancer treated with IGBT, and they suggested that local control rates greater than $95 \%$ can be achieved when the cumulative D90 for HR-CTV is 87 Gy or greater (27). Above this dose, local failure rate was $4 \%$ (3 of 68) compared to $20 \%$ (15 of 73) for doses less than $87 \mathrm{~Gy}$. Therefore, local control could be further optimized if dose escalation through the implementation of interstitial implant could be done in our practice.

Using a variety of treatment schedules of IGBT, several studies indicated the low rates of grade 3 and higher complications ranged from $0 \%$ to $14 \%(2-9,28)$. Except for the historic data reported by Vienna group (28), there was a paucity of studies comparing the late toxicities between
IGBT and 2DBT. In general, the cumulative rate of grade 2 or grade 3 and higher complications in 2DBT group were similar to that of these studies (2-9). Despite the majority of the urinary and rectal complications occurring within 2 to 3 years after the completion of therapy, the risk of developing late bladder complications might occur up to 25 years after treatment, as pointed out by Eifel et al. (29). Thus, a longterm observational study is essential to verify the true incidence of bladder complication. Interestingly, the mean cumulative EQD2 of D2cc for the bladder in our IGBT group was $67.1 \mathrm{~Gy}_{3}$, which was far less than the value of $101 \mathrm{~Gy}$, which could result in a $10 \%$ risk of grade 2 or more GU complications $(28,30)$. The disparity was due to the fact that the strategy of bladder dilatation was not adopted during our IGBT application. Given that the GI toxicities were not remarkably elevated by this approach, it can become a feasible method to minimize bladder dose.

The findings of this study should be interpreted cautiously because they represent a retrospective study design in a single institute. The median follow-up duration in the IGRT group was shorter than that of the 2DBT group. Nonetheless, several potential bias could be excluded when matching variables between the groups, such as lymph node status or histological types. In addition, although the benefit of the preferable dose distribution was intensified by using IMRT, a routine implementation of image-guided radiotherapy combined with timely adaptive radiotherapy might be the best approach. By reducing setup error and correcting for uncertainty after tumor regression, these approaches allow a reduction in the margin that is added to the CTV. In this way, the therapeutic index ought to be promoted. Finally, implementation of a combined interstitial-intracavitary applicator will be another approach to optimize the treatment result (31). The use of additional interstitial needles provides sufficient prescribed dose to eccentric tumors, whereas the dose to OARs was within standard limits for intracavitary brachytherapy alone. Accordingly, a combination of high-quality IMRT and IGBT will probably become a benchmarking guidance for the treatment of advanced cervical cancer.

In summary, this comparative study disclosed that primary control was similar when comparing IGBT with 2DBT for locally advanced cervical squamous cell carcinoma treated in the IMRT era. However, the therapeutic ratio could be increased by IGBT through minimizing the late toxicities. The result will be helpful to institutions where the costeffectiveness of IGBT is a concern, particularly where resources are limited. More long-term observational studies are required to verify these findings.

\section{Acknowledgements}

This study is supported in part by grants from China Medical University Hospital (DMR-107-186, and DMR-108-201). 
Table V. Multivariate logistic regression estimated odds ratios (OR) for developing grade 2 or grade 3 gastrointestinal (GI) and genitourinary (GU) complications after radiotherapy across different variables.

\begin{tabular}{|c|c|c|c|c|c|c|c|c|c|c|c|c|c|c|c|c|}
\hline \multirow[t]{3}{*}{ Variables } & \multicolumn{4}{|c|}{$\begin{array}{l}\geq \text { Grade } 2 \text { GI } \\
\text { complications }\end{array}$} & \multicolumn{4}{|c|}{$\begin{array}{l}\geq \text { Grade } 2 \text { GU } \\
\text { complications }\end{array}$} & \multicolumn{4}{|c|}{$\begin{array}{l}\geq \text { Grade } 2 \text { GI or GU } \\
\text { complications }\end{array}$} & \multicolumn{4}{|c|}{$\begin{array}{c}\geq \text { Grade } 3 \text { GI or GU } \\
\text { complications }\end{array}$} \\
\hline & Univariate & \multicolumn{3}{|c|}{ Multivariate } & Univariate & \multicolumn{3}{|c|}{ Multivariate } & Univariate & \multicolumn{3}{|c|}{ Multivariate } & Univariate & \multicolumn{3}{|c|}{ Multivariate } \\
\hline & $p$-Value $p$ & $p$-Value & OR & $95 \% \mathrm{CI}$ & I $p$-Value & $p$-Value & le OR & $95 \% \mathrm{CI}$ & $p$-Value & $p$-Value & OR & $95 \% \mathrm{CI}$ & $p$-Value & $p$-Value & OR & $95 \% \mathrm{CI}$ \\
\hline $\begin{array}{l}\text { Age (years) } \\
>65 \text { vs. } \leq 65\end{array}$ & 0.32 & 0.39 & & & 0.74 & 0.76 & & & 0.09 & 0.29 & & & 0.21 & 0.45 & & \\
\hline $\begin{array}{l}\text { Diabetes } \\
\text { negative } v s \text {. positive }\end{array}$ & 0.37 & 0.29 & & & 0.66 & 0.82 & & & 0.81 & 0.61 & & & 0.59 & 0.49 & & \\
\hline $\begin{array}{l}\text { FIGO stage (old) } \\
\text { IB2-IIB } v s \text {. IIIA-IVA }\end{array}$ & 0.50 & 0.33 & & & 0.82 & 0.96 & & & 0.73 & 0.46 & & & 0.80 & 0.66 & & \\
\hline FIGO stage (new) & & & & & & & & & & & & & & & & \\
\hline IB3-IIB vs. IIIA-IVA & 0.49 & 0.54 & & & 0.87 & 0.95 & & & 0.68 & 0.77 & & & 0.64 & 0.74 & & \\
\hline $\begin{array}{l}\text { Pelvic lymph node } \\
\text { negative } v s \text {. positive }\end{array}$ & 0.27 & 0.34 & & & 0.93 & 0.92 & & & 0.50 & 0.63 & & & 0.83 & 0.65 & & \\
\hline $\begin{array}{l}\text { Paraaortic lymph node } \\
\text { negative } v s \text {. positive }\end{array}$ & 0.40 & 0.33 & & & 0.70 & 0.60 & & & 0.35 & 0.27 & & & 0.04 & 0.026 & 3.43 & $\begin{array}{l}1.16 \sim \\
10.18\end{array}$ \\
\hline $\begin{array}{l}\text { Obstructive uropathy } \\
\text { negative } v s \text {. positive } \\
\text { Brachytherapy number }\end{array}$ & 0.26 & 0.36 & & & 0.57 & 0.75 & & & 0.21 & 0.32 & & & 0.34 & 0.76 & & \\
\hline 4 vs. $\geq 5$ & 0.55 & 0.67 & & & 0.96 & 0.81 & & & 0.72 & 0.40 & & & 0.45 & 0.55 & & \\
\hline 2DBT vs. IGBT & 0.013 & 0.015 & 0.40 & $\begin{array}{c}0.19 \sim \\
0.84\end{array}$ & 0.002 & 0.009 & 0.14 & $\begin{array}{c}0.05 \sim \\
0.69\end{array}$ & $<0.001$ & 0.001 & 0.30 & $\begin{array}{c}0.15 \sim \\
0.60\end{array}$ & 0.001 & 0.003 & 0.10 & $\begin{array}{c}0.02 \\
\sim 0.45\end{array}$ \\
\hline
\end{tabular}

CI, Confidence interval; FIGO, International Federation of Gynecology and Obstetrics; 2DBT, two-dimensional brachytherapy; IGBT, image-guided brachytherapy.

\section{Ethical approval}

This study was approved by a local institutional review board [CMUH 107-REC3-119].

\section{Authors' Contributions}

SW Chen was responsible for the study design. All authors collected the data and provided some intellectual content. JA Liang and SW Chen performed statistical analyses, interpreted data, and drafted the article. SW Chen approved the version to be submitted. All authors read and approved the final manuscript.

\section{Conflicts of Interest}

All Authors declare no conflicts of interest.

\section{References}

1 Ferlay J, Soerjomataram I, Dikshit R, Eser S, Mathers C, Rebelo M, Parkin DM, Forman D and Bray F: Cancer incidence and mortality worldwide: Sources, methods and major patterns in globocan 2012. Int J Cancer 136(5): E359-386, 2015. PMID: 25220842. DOI: $10.1002 /$ ijc. 29210

2 Potter R, Dimopoulos J, Georg P, Lang S, Waldhausl C, Wachter-Gerstner N, Weitmann H, Reinthaller A, Knocke TH,
Wachter S and Kirisits C: Clinical impact of mri assisted dose volume adaptation and dose escalation in brachytherapy of locally advanced cervix cancer. Radiother Oncol 83(2): 148-155, 2007. PMID: 17531904. DOI: 10.1016/j.radonc.2007.04.012

3 Charra-Brunaud C, Harter V, Delannes M, Haie-Meder C, Quetin P, Kerr C, Castelain B, Thomas L and Peiffert D: Impact of 3d image-based pdr brachytherapy on outcome of patients treated for cervix carcinoma in france: Results of the french stic prospective study. Radiother Oncol 103(3): 305-313, 2012. PMID: 22633469. DOI: 10.1016/j.radonc .2012.04.007

4 Tan LT, Coles CE, Hart C and Tait E: Clinical impact of computed tomography-based image-guided brachytherapy for cervix cancer using the tandem-ring applicator - the addenbrooke's experience. Clin Oncol (R Coll Radiol) 21(3): 175-182, 2009. PMID: 19101130. DOI: 10.1016/j.clon.2008.12.001

5 Potter R, Georg P, Dimopoulos JC, Grimm M, Berger D, Nesvacil N, Georg D, Schmid MP, Reinthaller A, Sturdza A and Kirisits C: Clinical outcome of protocol based image (mri) guided adaptive brachytherapy combined with $3 \mathrm{~d}$ conformal radiotherapy with or without chemotherapy in patients with locally advanced cervical cancer. Radiother Oncol 100(1): 116-123, 2011. PMID: 21821305. DOI: $10.1016 /$ j.radonc.2011.07.012

6 Kang HC, Shin KH, Park SY and Kim JY: 3d ct-based highdose-rate brachytherapy for cervical cancer: Clinical impact on late rectal bleeding and local control. Radiother Oncol 97(3): 507-513, 2010. PMID: 21074881. DOI: 10.1016/j.radonc. 2010.10 .002 
7 Gill BS, Kim H, Houser CJ, Kelley JL, Sukumvanich P, Edwards RP, Comerci JT, Olawaiye AB, Huang M, Courtney-Brooks M and Beriwal S: Mri-guided high-dose-rate intracavitary brachytherapy for treatment of cervical cancer: The university of pittsburgh experience. Int J Radiat Oncol Biol Phys 91(3): 540547, 2015. PMID: 25680598. DOI: 10.1016/ j.jirobp.2014.10.053

8 Narayan K, van Dyk S, Bernshaw D, Rajasooriyar C and Kondalsamy-Chennakesavan S: Comparative study of $\mathrm{ldr}$ (manchester system) and hdr image-guided conformal brachytherapy of cervical cancer: Patterns of failure, late complications, and survival. Int J Radiat Oncol Biol Phys 74(5): 1529-1535, 2009. PMID: 19473780. DOI: 10.1016/j.jirobp.2008. 10.085

9 Sturdza A, Potter R, Fokdal LU, Haie-Meder C, Tan LT, Mazeron R, Petric P, Segedin B, Jurgenliemk-Schulz IM, Nomden C, Gillham C, McArdle O, Van Limbergen E, Janssen H, Hoskin P, Lowe G, Tharavichitkul E, Villafranca E, Mahantshetty U, Georg P, Kirchheiner K, Kirisits C, Tanderup $\mathrm{K}$ and Lindegaard JC: Image guided brachytherapy in locally advanced cervical cancer: Improved pelvic control and survival in retroembrace, a multicenter cohort study. Radiother Oncol 120(3): 428-433, 2016. PMID: 27134181. DOI: 10.1016/ j.radonc.2016.03.011

10 Lin AJ, Kidd E, Dehdashti F, Siegel BA, Mutic S, Thaker PH, Massad LS, Powell MA, Mutch DG, Markovina S, Schwarz J and Grigsby PW: Intensity modulated radiation therapy and image-guided adapted brachytherapy for cervix cancer. Int $\mathbf{J}$ Radiat Oncol Biol Phys 103(5): 1088-1097, 2019. PMID: 30445171. DOI: 10.1016/j.ijrobp.2018.11.012

11 Otter S, Franklin A, Ajaz M and Stewart A: Improving the efficiency of image guided brachytherapy in cervical cancer. J Contemp Brachytherapy 8(6): 557-565, 2016. PMID: 28115963. DOI: $10.5114 /$ jcb.2016.64452

12 Zubizarreta EH, Fidarova E, Healy B and Rosenblatt E: Need for radiotherapy in low and middle income countries - the silent crisis continues. Clin Oncol (R Coll Radiol) 27(2): 107-114, 2015. PMID: 25455407. DOI: 10.1016/j.clon.2014.10.006

13 Bhatla N, Aoki D, Sharma DN and Sankaranarayanan R: Cancer of the cervix uteri. Int J Gynaecol Obstet 143(Suppl 2): 22-36, 2018. PMID: 30306584. DOI: 10.1002/ijgo.12611

14 Huang YT, Wang CC, Tsai CS, Lai CH, Chang TC, Chou HH, Hsueh S, Chen CK, Lee SP and Hong JH: Long-term outcome and prognostic factors for adenocarcinoma/adenosquamous carcinoma of cervix after definitive radiotherapy. Int J Radiat Oncol Biol Phys 80(2): 429-436, 2011. PMID: 20542643. DOI: 10.1016/j.ijrobp.2010.02.009

15 Niibe Y, Kenjo M, Onishi H, Ogawa Y, Kazumoto T, Ogino I, Tsujino K, Harima Y, Takahashi T and Anbai A: High-dose-rate intracavitary brachytherapy combined with external beam radiotherapy for stage iiib adenocarcinoma of the uterine cervix in japan: A multi-institutional study of japanese society of therapeutic radiology and oncology 2006-2007 (study of jastro 2006-2007). Jpn J Clin Oncol 40(8): 795-799, 2010. PMID: 20444747. DOI: $10.1093 /$ jjco/hyq053

16 Chen SW, Liang JA, Hung YC, Yeh LS, Chang WC, Lin WC and Chien CR: Does initial 45gy of pelvic intensity-modulated radiotherapy reduce late complications in patients with locally advanced cervical cancer? A cohort control study using definitive chemoradiotherapy with high-dose rate brachytherapy. Radiol Oncol 47(2): 176-184, 2013. PMID: 23801915. DOI: 10.2478/raon-2013-0011
17 Lim K, Small W, Jr., Portelance L, Creutzberg C, JurgenliemkSchulz IM, Mundt A, Mell LK, Mayr N, Viswanathan A, Jhingran A, Erickson B, De los Santos J, Gaffney D, Yashar C, Beriwal S, Wolfson A, Taylor A, Bosch W, El Naqa I, Fyles A and Gyn IC: Consensus guidelines for delineation of clinical target volume for intensity-modulated pelvic radiotherapy for the definitive treatment of cervix cancer. Int J Radiat Oncol Biol Phys 79(2): 348-355, 2011. PMID: 20472347. DOI: 10.1016/ j.ijrobp.2009.10.075

18 Taylor A, Rockall AG, Reznek RH and Powell MEB: Mapping pelvic lymph nodes: Guidelines for delineation in intensitymodulated radiotherapy. Int J Radiat Oncol Biol Phys 63(5): 1604-1612, 2005. DOI: 10.1016/j.ijrobp.2005.05.062

19 van de Bunt L, Jurgenliemk-Schulz IM, de Kort GA, Roesink JM, Tersteeg RJ and van der Heide UA: Motion and deformation of the target volumes during imrt for cervical cancer: What margins do we need? Radiother Oncol 88(2): 233-240, 2008. PMID: 18237798. DOI: 10.1016/j.radonc.2007.12.017

20 Chen SW, Liang JA, Hung YC, Yeh LS, Chang WC, Yang SN and Lin FJ: Geometrical sparing factors for the rectum and bladder in the prediction of grade 2 and higher complications after high-dose-rate brachytherapy for cervical cancer. Int J Radiat Oncol Biol Phys 75(5): 1335-1343, 2009. PMID: 19386443. DOI: 10.1016/j.ijrobp.2008.12.018

21 Potter R, Haie-Meder C, Van Limbergen E, Barillot I, De Brabandere M, Dimopoulos J, Dumas I, Erickson B, Lang S, Nulens A, Petrow P, Rownd J, Kirisits C and Group GEW: Recommendations from gynaecological (gyn) gec estro working group (ii): Concepts and terms in $3 \mathrm{~d}$ image-based treatment planning in cervix cancer brachytherapy-3d dose volume parameters and aspects of $3 \mathrm{~d}$ image-based anatomy, radiation physics, radiobiology. Radiother Oncol 78(1): 67-77, 2006. PMID: 16403584. DOI: 10.1016/j.radonc.2005.11.014

22 Health UDo and Services H: Common terminology criteria for adverse events (ctcae) version 4.0. National Institutes of Health, National Cancer Institute 4(03), 2009. Available from: https:// ctep.cancer.gov/protocoldevelopment/electronic_applications/ctc. htm

23 Naik A, Gurjar OP, Gupta KL, Singh K, Nag P and Bhandari V: Comparison of dosimetric parameters and acute toxicity of intensity-modulated and three-dimensional radiotherapy in patients with cervix carcinoma: A randomized prospective study. Cancer Radiother 20(5): 370-376, 2016. PMID: 27368915. DOI: 10.1016/j.canrad.2016.05.011

24 Gandhi AK, Sharma DN, Rath GK, Julka PK, Subramani V, Sharma S, Manigandan D, Laviraj MA, Kumar S and Thulkar S: Early clinical outcomes and toxicity of intensity modulated versus conventional pelvic radiation therapy for locally advanced cervix carcinoma: A prospective randomized study. Int J Radiat Oncol Biol Phys 87(3): 542-548, 2013. PMID: 24074927. DOI: 10.1016/j.ijrobp.2013.06.2059

25 Hasselle MD, Rose BS, Kochanski JD, Nath SK, Bafana R, Yashar CM, Hasan Y, Roeske JC, Mundt AJ and Mell LK: Clinical outcomes of intensity-modulated pelvic radiation therapy for carcinoma of the cervix. Int J Radiat Oncol Biol Phys 80(5): 1436-1445, 2011. PMID: 20708346. DOI: 10.1016/ j.ijrobp.2010.04.041

26 Kidd EA, Siegel BA, Dehdashti F, Rader JS, Mutic S, Mutch DG, Powell MA and Grigsby PW: Clinical outcomes of definitive intensity-modulated radiation therapy with fluorodeoxyglucose- 
positron emission tomography simulation in patients with locally advanced cervical cancer. Int J Radiat Oncol Biol Phys 77(4): 1085-1091, 2010. PMID: 19880262. DOI: 10.1016/j.ijrobp.2009.06.041

27 Dimopoulos JC, Lang S, Kirisits C, Fidarova EF, Berger D, Georg P, Dorr W and Potter R: Dose-volume histogram parameters and local tumor control in magnetic resonance image-guided cervical cancer brachytherapy. Int J Radiat Oncol Biol Phys 75(1): 56-63, 2009. PMID: 19289267. DOI: 10.1016/ j.ijrobp.2008.10.033

28 Georg P, Potter R, Georg D, Lang S, Dimopoulos JC, Sturdza AE, Berger D, Kirisits C and Dorr W: Dose effect relationship for late side effects of the rectum and urinary bladder in magnetic resonance image-guided adaptive cervix cancer brachytherapy. Int J Radiat Oncol Biol Phys 82(2): 653-657, 2012. PMID: 21345618. DOI: 10.1016/j.ijrobp.2010.12.029

29 Eifel PJ, Levenback C, Wharton JT and Oswald MJ: Time course and incidence of late complications in patients treated with radiation therapy for figo stage ib carcinoma of the uterine cervix. Int J Radiat Oncol Biol Phys 32(5): 1289-1300, 1995. PMID: 7635768. DOI: 10.1016/0360-3016(95)00118-I
30 Viswanathan AN, Lee LJ, Eswara JR, Horowitz NS, Konstantinopoulos PA, Mirabeau-Beale KL, Rose BS, von Keudell AG and Wo JY: Complications of pelvic radiation in patients treated for gynecologic malignancies. Cancer 120(24): 3870-3883, 2014. PMID: 25056522. DOI: 10.1002/cncr.28849

31 Kirisits C, Lang S, Dimopoulos J, Berger D, Georg D and Potter $\mathrm{R}$ : The vienna applicator for combined intracavitary and interstitial brachytherapy of cervical cancer: Design, application, treatment planning, and dosimetric results. Int J Radiat Oncol Biol Phys 65(2): 624-630, 2006. PMID: 16690444. DOI: 10.1016/j.ijrobp.2006.01.036

Received March 31, 2019

Revised April 29, 2019

Accepted May 2, 2019 